\title{
Pinch Analysis as a Knowledge Management Tool for Optimization in Supply Chain
}

\author{
Olusegun Folorunso \\ Department of Computer Science \\ University of Agriculture Abeokuta, Ogun State, Nigeria \\ E-mail: folorunsolusegun@yahoo.com \\ Gladys Adewale \\ Department of Computer Science \\ University of Agriculture Abeokuta, Ogun State, Nigeria \\ E-mail: gladys_adewale@yahoo.com \\ Adewale Opeoluwa Ogunde \\ Redeemer's University (RUN), Redemption City, Mowe, Ogun State, Nigeria \\ E-mail: adewaleogunde@yahoo.com \\ Julius .Olatunji. Okesola \\ Departments of Computer \& Information Science, Tai Solarin University of Education \\ Ijebu-Ode, Nigeria \\ E-mail: tunji_okesola@yahoo.co.uk
}

\begin{abstract}
Supply chain managers are trying to maximize the profitable operation of their manufacturing and distribution supply chain, but due to global competition in process industries and complexities of the supply chain processes together with large computational times, it has made optimization of supply chain management (SCM) quite difficult. Recently, Knowledge management (KM) is a new important information technology-based business paradigm for achieving competitive advantage, and it is no surprise that it has received so much attention from researchers. This paper therefore deploys Pinch Analysis, a practicable tool that entails less complex mathematics compared to many other optimization tools, to manage critical knowledge generated in supply chains. In this study, demand and supply explicit knowledge from the organization was represented as composites for the pinch analysis. The developed system gave supply chain managers new insights into SCM and thus aiding quick decision-making and on the overall helped to achieve the much needed competitive advantage.
\end{abstract}

Keywords: Knowledge Management, Supply Chain Management, Pinch Analysis, Optimization, Production

\section{Introduction}

A critical decision companies are faced with on a regular basis is the ordering of products and/or raw materials. Supply Chain Management (SCM) is the oversight of materials, information, and finances as they move in a process from supplier to manufacturer to wholesaler to retailer to consumer. It is said that the ultimate goal of any effective supply chain management system is to reduce inventory. Employing appropriate and standard optimization algorithms help to solve supply chain optimization problems (McDonald and Karmi, 1997). Such problems include high expenses of documentation, time consumption, computational complexities, low quality of data, low degree of accuracy and limited user acceptance (Chopra and Mendl, 2001).

Knowledge management in a business perspective is treating the knowledge component of business activities as an explicit concern of business reflected in strategy, policy, and practice at all levels of the organization; and, 
making a direct connection between an organization's intellectual assets-both explicit (recorded) and tacit (personal know-how) - and positive business results. Knowledge, an undisputable asset in changing organization's business paradigm is of two forms.

Supply chain managers are trying to maximize the profitable operation of their manufacturing and distribution supply chain, but due to global competition in process industries and complexities of the supply chain processes together with large computational times, it has made optimization of supply chain management (SCM) quite difficult. There is therefore the need to explore other possible optimization tools and methods as a way of proffering solution to the identified problems. This paper therefore deploys Pinch Analysis, which is a methodology for minimizing energy consumption of chemical processes by calculating thermodynamically feasible energy targets (or minimum energy consumption) and achieving them by optimizing heat recovery systems, energy supply methods and process operating conditions, in the critical KM of supply chains data.

The rest of the paper is organized as follows. Section 2 reviewed the literature. Section 3 contains the design which is used in achieving the set objectives. Section 4 shows the analysis and discussion of results realized from the implementation while section 5 draws conclusion with some future works suggested.

\section{Literature Review}

\subsection{Knowledge Management (KM)}

Knowledge management KM has become an important component of enterprise information systems. KM has recently received considerable attention in the computer information systems community and is continuously gaining interest by industry, enterprises and academic (Metaxiotics and Psarras, 2003). Today KM is the subject matter of much literature, discussion, planning and some action (Nonaka, 1991; Davenport and Prusak, 1998; Metaxiotics et al, 2002; Singh and Kant, 2007; Folorunso and Ogunseye, 2008). Knowledge management is the methodology for systematically gathering, organizing and dissemination of facts called information. This information has to be true by itself.

Knowledge can be tacit or explicit (Dalkir, 2005). Tacit knowledge is difficult to articulate and also difficult to put into words, text, or drawings. In contrast, explicit knowledge represents content that has been captured in some tangible form such as words, audio recordings, or images. Moreover, tacit knowledge tends to reside "within the heads of knowers," whereas explicit knowledge is usually contained within tangible or concrete media (Dalkir, 2005).

The idea of a KM system is to enable employees to have ready access to the organization's documented base of facts, sources of information, and solutions (Benbya, 2008). Sharing information organization wide can lead to more effective engine design and it could lead to ideas for new or improved equipment. Today, in the market place of e-business, KM initiatives are used to systematically leverage information and expertise to improve organizational Responsiveness, Innovation, Competency and Efficiency (RICE).

\subsection{Supply Chain Management (SCM)}

Supply chain optimization addresses the general supply chain problem of delivering products to customers at the lowest cost and highest profit. This includes trading off the costs of inventory, transportation, distributing and manufacturing. Supply chain for a business includes all stages involved directly or indirectly in fulfilling demand for a customer.

Arnold and Chapman (2001) defined supply chain management as a process of integrating/utilizing suppliers, manufacturers, warehouses, and retailers, so that goods are produced and delivered a the right quantities, and at the right time, while minimizing costs as well as satisfying customer requirements. Fig 1 shows the structure of a typical supply chain. It consists of a number of organizations - beginning with suppliers, who provide raw materials to manufacturers, which manufacture products and keep those manufactured goods in the warehouses. Then they send them to wholesales or distribution centers that ship the goods to retailers. Different industries have slightly different structures of the supply chain networks (Fig 1).

Traditionally, marketing, distribution, planning, manufacturing, and the purchasing organizations along the supply chain operated independently. These organizations have their own objectives and these are often conflicting. Marketing's objective of high customer service and maximum sales conflict with manufacturing and distribution goals. Many manufacturing operations are designed to maximize throughput and lower costs with little consideration for the impact on inventory levels and distribution capabilities. The result of these factors is that there is not a single, integrated plan for the organization.

The objective of SCM is to create the most value, not simply for the company but for the whole supply chain 
network, including the end customer. Consequently, supply chain process integration and re-engineering initiatives should be aimed at boosting total process efficiency and effectiveness across members of the supply chain.

Supply chain is typically viewed to lie between fully vertically integrated firms, where the entire material flow is owned by a single flow and those where each channel member operates independently. Therefore coordination between the various players in the chain is key in its effective management. The goal of supply chain management is to integrate suppliers, manufacturers, warehouses, and stores efficiently, so that merchandise is produced and distributed in the right quantities, at the right locations, and at the right times (Singhvi, A. (2002).

\subsection{Pinch Analysis}

Pinch analysis is a methodology for minimizing energy consumption of chemical processes by calculating thermodynamically feasible energy targets and achieving them by optimizing heat recovery systems, energy supply methods and process operating conditions. Pinch analysis has been extended beyond energy applications. It now includes Mass Exchange Networks, Water Pinch (Wang and Smith, 1994), Hydrogen Pinch (Hallale, 2002).

Pinch analysis (or pinch technology) is a rigorous, structured approach that may be used to tackle a wide range of improvements related to process and site utility. This includes opportunities such as reducing operating costs, debottlenecking processes, improving efficiency, and reducing and planning capital investment. Pinch analysis uses a holistic approach to process design and optimization by exploiting the interactions between different units in order to employ resources effectively and minimize costs. The key insight is the Pinch point.

Pinch is defined as the most constrained point in the process. The proposed approach determines the optimized point in supply chain taking the pinch into consideration through graphical representation of explicit demand and supply knowledge. At the pinch point, the material flows in a supply chain are balanced and problem decomposition is possible. Major reasons for the success of pinch analysis are the simplicity of the concepts behind the approach, and the impressive results it has been obtained worldwide.

A summary of the key concepts, their significance, and the nomenclature used in pinch analysis is given below:

- Combined (Hot and Cold) Composite Curves: they are used to predict targets for

i. Minimum energy (both hot and cold utility) required,

ii. Minimum network area required, and

iii. Minimum number of exchanger units required.

- DTmin and Pinch Point: the DTmin value determines how closely the hot and cold composite curves can be pinched (or optimized).

- Grand Composite Curve: this curve selects appropriate levels of utilities (maximize cheaper utilities) to meet over all energy requirements.

- Energy and Capital Cost Targeting: this is used to determine the optimum level of heat recovery or the optimum DTmin value, by balancing energy and capital costs. Using this method, it is possible to obtain an accurate estimate (within 10-15\%) of overall heat recovery system costs without having to design the system. The essence of the pinch approach is the speed of economic evaluation.

- Plus /minus and Appropriate Placement Principles: The Plus/Minus principle provides guidance regarding how a process can be modified in order to reduce associated utility needs and costs. This principle states that "The overall energy needs of a process can be further reduced by introducing process changes (changes in the process heat and material balance). The number of possible process changes is nearly infinite. By applying the pinch rules later discussed, it is possible to identify changes in the appropriate process parameter that will have a favorable impact on energy consumption.

The Appropriate Placement Principles provide insights for proper integration of key equipments like distillation columns, evaporators, furnaces, heat engines, heat pumps, etc. in order to reduce the utility requirements of the combined system. This Principle states that the operations of key equipment in process should be integrated in such a way that there is reduction in the utility requirement of the combined system.

- Total Site Analysis: This concept enables the analysis of the energy usage for an entire plant site that consists of several processes served by a central utility system. 


\subsection{Rules of Pinch Analysis}

A well defined set of rules must be adhered to step-wisely in any Pinch Analysis problem. These are:

- Identification of Hot, Cold and Utility Streams in the process

i. Hot Streams are the streams that must be cooled or are available to be cooled. e.g. product cooling before storage

ii. Cold Streams are those that must be heated e.g. feed preheat before a reactor.

iii. Utility Streams are used to heat or cool process streams, when heat exchange between process streams is not practical or economic. A number of different hot utilities (steam, hot water, etc.) and cold utilities (cooling water, air, refrigerant, etc.) are used in industry.

- Thermal Data extraction for the process and Utility streams.

For each hot, cold and utility stream identified, the following thermal data is extracted from the process material and heat balance flow sheet:

i. Initial temperature $\left(\mathrm{Ti}^{\circ} \mathrm{C}\right)$ : This is the temperature at which the stream is available.

ii. Target temperature $\left(\mathrm{Tt}^{\circ} \mathrm{C}\right)$ : this is the temperature the stream must be taken to.

iii. Heat capacity flow rate: $\left(\mathrm{CP} \mathrm{kW} /{ }^{\circ} \mathrm{C}\right)$ : This is the product of flow rate $(\mathrm{m}) \mathrm{in} \mathrm{kg} / \mathrm{sec}$ and specific heat $(\mathrm{Cp}$ $\left.\mathrm{kJ} / \mathrm{kg}{ }^{\circ} \mathrm{C}\right)$.

$\mathrm{CP}=\mathrm{m} \times \mathrm{Cp}$

iv. Enthalpy Change $(\mathrm{dH})$ : This is associated with a stream passing through the exchanger is given by the First Law of Thermodynamics:

First Law energy equation: $\mathrm{d} H=\mathrm{Q} \pm \mathrm{W}$

In a heat exchanger, no mechanical work is being performed:

$\mathrm{W}=0$ (zero)

The above equation reduces to $\mathrm{d} \mathrm{H}=\mathrm{Q}$, where $\mathrm{Q}$ represents the heat supply or demand associated with the stream. It is given by the relationship:

$\mathrm{Q}=\mathrm{CP} \times(\mathrm{Ti}-\mathrm{Tt})$.

Enthalpy Change,

$\mathrm{dH}=\mathrm{CP} \times(\mathrm{Ti}-\mathrm{Tt})$

Recognizing the significance of the pinch temperature allows energy targets to be realized by design of appropriate heat recovery network. The pinch divides the process into two separate systems each of which is in enthalpy balance with the utility. The pinch point is unique for each process. Above the pinch, only the hot utility is required. Hence, for an optimum design, no heat should be transferred across the pinch. This is known as the key concept in Pinch Technology.

\section{The Pinch Concept in Supply Chains KM}

The power of pinch analysis lies in the physical insight it provides into the supply chain process. Material flows, material hold up and time for the three important indicators of a supply chain. Pinch analysis elegantly handles these parameters by plotting demand and production composites on a time vs. material quantity plot (Singhvi, 2002). Some of the variables used in the interpretation of the pinch concept in supply chains KM are:

i. The hot stream is represented as demand $\mathrm{D}(\mathrm{t})$ and the cold stream, as production $\mathrm{P}(\mathrm{t})$.

ii. The DTmin represented as DMmin in the supply chain, determines how closely the demand and production composite curves can be pinched (or optimized).

iii. At the pinch, the material flows in a supply chain are balanced and problem decomposition is possible.

iv. The demand composite curve $\mathrm{D}(\mathrm{t})$ is simply a plot of the cumulative demand as a function of time, and needs to be matched by a production composite curve $\mathrm{P}(\mathrm{t})$. The demand has to be met by supply of products.

\subsection{Pinch Algorithm for KM in Supply Chain}

The output for the program should show a time-material graph having two composite curves (production and demand) on it.

Step 1) Input the number of months 
Step 2) Input values (amount of material) for production and demand respectively monthly (i.e. January, February and so on).

Step 3) Restriction for the values inputted:

If value inputted for production is greater than the corresponding value inputted for demand, throw an exception: "excess supply".

Step 4) To find the DMmin:

For each value of production and corresponding value of demand, find the minimum of (Demand-Production). That is call a function in a FOR loop $\operatorname{MIN}(\mathrm{D}(\mathrm{t})-\mathrm{P}(\mathrm{t}))$.

Step 5) For optimization:

Add DMmin/2 to all values of production and subtract it from all values of demand.

Step 6) Pinch point is the point where value of production $=$ value of demand (i.e. the point at which $\mathrm{D}(\mathrm{t})-\mathrm{P}(\mathrm{t})=$ $0)$.

Mathematically, the above algorithm can be represented as:

Minimize $D(t)-P(t)$

Subject to: $\mathrm{D}(\mathrm{t})-\mathrm{P}(\mathrm{t})>0$

Fig 2 depicts a graphical model briefly describing the algorithm in section 3.1

\subsection{Data Source}

The pinch analysis approach is illustrated for a single product scenario using explicit demand and supply knowledge collected from Bobo foods and beverages limited, Nigeria. The demand for amount of materials is usually higher than its supply so as to prevent excess supply which is uneconomical. Also, the data collected was detailed with the monthly description of production of goods made by the company on monthly basis and the corresponding knowledge of demand and supply for that year. The proposed optimization approach has a user-friendly interface that requires user(s) to input the number of months and the respective values of demand and supply knowledge for those months. Thus, the system is not restricted to just twelve (12) months of the year.

\subsection{Architecture of the proposed system}

The proposed knowledge management in supply chains architecture is described in figure 3 . Critical knowledge of demand and supply in production gathered over the years by the supply chain managers are shared with knowledge managers in the organization.

The knowledge managers put the acquired knowledge in the organizations knowledge repositories for easy retrieval. The information in the knowledge repositories is then passed through the developed Supply Chain KM System that operates on the pinch analysis method. The result of this stage is the pinch point. The pinch point is interpreted by the knowledge managers, interpreted and then passed to the supply chain managers for subsequent actions and implementation.

\section{System Implementation}

A web-based application was developed using Visual studio 2008 (.NET Framework), connecting the knowledge repository stored in the Microsoft SQL server 2005 to the program source code so that whatever entries inputted by the user is automatically stored in the repository. This optimization package is structured into one database with two tables.

\subsection{The Entry Form}

This form requires the user to input the year (in this case, between 1998 and 2014), the different months of the year with their corresponding values of supply and demand knowledge. After which the user clicks on the "save" key which stores the values in the knowledge repository.

\subsection{The Entry Table}

After inputting the values needed for optimization, the "next" button is clicked. This shows a table which contains all the values of demand and supply knowledge inputted earlier with their corresponding differences, that is, the respective differences between demand and supply for each month is calculated. This is shown in tables 1 and 2 .

Table 2 allows the user to either edit or delete any particular record. To calculate the DMmin value from all the differences of demand and supply knowledge earlier calculated, the minimum value of these differences are 
taken. This is shown in the interface that requires the user to click on the "calculate DMmin" button and then the "next" button. The value of DMmin is returned.

\subsection{The Optimized Entry Table}

The calculated value of DMmin earlier returned is used to optimize the initial values of demand and supply knowledge. This is done by subtracting half $(1 / 2)$ of the DMmin value from the values of demand and adding it to the values of supply for each month earlier inputted. The point at which the value of the optimized demand is equal to the optimized supply is returned as the pinch (optimized) point of production. The structure of this table is shown in table 2.

\subsection{Design of the Output on Excel Sheet}

The data gotten from Bobo Foods and Beverages Limited, a manufacturing company in Nigeria that deals with the production of packaged drinks, was used as the initial entries inputted. The output of both the initial and optimized data is shown on the material-time graph of the data inputted (fig 4).

The DMmin as earlier discussed represents the minimum difference between quantity of materials demanded and those produced between January and November. This value occurred in June. The DMmin is used to calculate the pinch (optimized) point for transactions for that year. Hence, the pinch point occurred invariably in the month of June.

After calculating the DMmin, it was then used to evaluate the optimized demand and production entries. These entries were then used to plot the chart in figure 5 which was used to determine the pinch point for the data entries entered.

\section{Conclusion and future works}

A proposed KM tool, pinch analysis, was used to ease the work of supply chain managers in the optimization of supply chains. The implementation and optimization of Supply chains using Pinch analysis as a tool to manage critical knowledge generated in this environment can be seen as a giant stride towards developing effective Supply Chain Management System, where most of the problems associated with other optimization techniques can be completely eliminated. Pinch analysis, used a graphical procedure involving production and demand composites, and also showed a good understanding of the production planning problem with optimal solutions. Its graphical procedure also makes it faster and easier to implement unlike other optimization tools. Further research may examine the optimization of the other aspects of supply chain flows, that is, the information flow and the financial (cash) flow using pinch analysis as an optimization tool.

\section{References}

Arnold, T. \& Chapman. (2001). Introduction to Materials Management 4th edition, Prentice Hall, Inc.

Benbya, H. (2008). Knowledge Management Systems Implementation: Lessons from the Silicon Valley. Oxford, Chandos Publishing.

Chopra, S., Meindl P. (2001). Supply Chain Management: Strategy, Planning and Operation, Pearson Education Inc.

Dalkir K. (2005). Knowledge Management in Theory and Practice. McGill University, Elsevier Butterworth-Heinemann 30 Corporate Drive, Suite 400, Burlington, MA 01803, USA Linacre House, Jordan Hill, Oxford OX2 8DP, UK, Elsevier Inc.

Davenport, T. and Prusak, L. (1998). Working knowledge: managing what your organization knows, Harvard Business School pre, Boston, MA.

Folorunso O., Ogunseye S. O. (2008). Applying an Enhanced Technology Acceptance Model to Knowledge Management in Agricultural Extension Services. Data. Sci. J. (7).

Hallale P. Ladet, Colored Petri Nets. (1986). A Tool for Modeling, Validation, and Simulation of FMS, in Flexible Manufacturing Systems: Methods and Studies (ed. A.Kusiak), Elsevier, New York, 271-281.

McDonald, C., Karimi, I. A. (1997). Planning and Scheduling of Parallel Semi-continuous Processes. 1. Production planning. Industrial and Engineering Chemistry Research, pg 36, 2691.

Metaxiotis, K., Psarras, J. and Papastefaratos, S. (2002). Knowledge and information management in e-learning environment: the user agent architecture. Information management and computer security, vol. 10 No 4, pp $165-70$

Metaxistis, K. and Psarras, J. (2003). Applying knowledge management in higher Education the creation of a 
learning organization, Journal of Information and knowledge management, vol.2 No. 4, pp 353-9.

Nonaka, I. (1991). The knowledge-creating company. Harvard Business Review, Vol.69, pp 96-104.

Singhvi, A. (2002). Multi-level planning of supply chains. M.Tech. Thesis, Indian Institute of Technology, Bombay.

Singh, M. and Kant. R. (2007). Knowledge management as competitive edge for Indian engineering industries. in: Proc. of the International Conference on Quality and Reliability, Chiang Mai, Thailand, 2007, 398-403. 5-7 November, pp. 398-403.

Wang, Y. P., Smith R. (1994). Wastewater minimization. Chemical Engineering Science, pg 49, 981-1006.

Table 1. Initial Entries of Demand and Supply Knowledge

\begin{tabular}{|l|r|r|}
\hline Month & Demand & Supply \\
\hline January & 140000 & 120000 \\
\hline February & 170000 & 130000 \\
\hline March & 200000 & 180000 \\
\hline April & 198000 & 182000 \\
\hline May & 170000 & 165000 \\
\hline June & 165000 & 162000 \\
\hline July & 135000 & 130000 \\
\hline August & 130000 & 125000 \\
\hline September & 200000 & 175000 \\
\hline October & 240000 & 200000 \\
\hline November & 265000 & 245000 \\
\hline
\end{tabular}


Table 2. Initial Entries Using Web- application

\begin{tabular}{|l|r|r|rr|c|}
\hline Month & $\begin{array}{l}\text { Entries on } \\
\text { Production }\end{array}$ & $\begin{array}{l}\text { Entries on } \\
\text { Demand }\end{array}$ & $\begin{array}{l}\text { (Difference in Demand } \\
\text { and Production) }\end{array}$ & Year \\
\hline January & 120000 & 140000 & 20000 & 2008 \\
\hline February & 130000 & 170000 & 40000 & 2008 \\
\hline March & 180000 & 200000 & 20000 & 2008 \\
\hline April & 182000 & 198000 & 16000 & 2008 \\
\hline May & 165000 & 170000 & 5000 & 2008 \\
\hline June & 162000 & 165000 & 3000 & 2008 \\
\hline July & 130000 & 135000 & 5000 & 2008 \\
\hline August & 125000 & 130000 & 5000 & 2008 \\
\hline September & 175000 & 200000 & 25000 & 2008 \\
\hline October & 200000 & 240000 & & 40000 & 2008 \\
\hline November & 245000 & 265000 & & 20000 & 2008 \\
\hline
\end{tabular}

Select the year for which you would like to calculate the DMIN Value : 2008

\section{Calculate DMmin}

The DMin Value is the least value of the difference for entries of Demand and Supply

It is calculated as follows: MIN(Difference)/2

The Value of the DMIN for the entries shown above is $\mathbf{1 5 0 0}$

Table 3. Optimized Values for Demand and Supply Knowledge

\begin{tabular}{|c|c|c|c|c|}
\hline & Year & Month & Optimized Supply & Optimized Demand \\
\hline$\Rightarrow$ & 2008 & January & 121500 & 138500 \\
\hline$\Rightarrow$ & 2008 & February & 131500 & 168500 \\
\hline$\rightarrow$ & 2008 & March & 181500 & 198500 \\
\hline$\rightarrow$ & 2008 & April & 183500 & 196500 \\
\hline$\rightarrow$ & 2008 & May & 166500 & 168500 \\
\hline$\rightarrow$ & 2008 & June & 163500 & 163500 \\
\hline$\rightarrow$ & 2008 & July & 131500 & 133500 \\
\hline$\rightarrow$ & 2008 & August & 126500 & 128500 \\
\hline$\rightarrow$ & 2008 & September & 176500 & 198500 \\
\hline$\Rightarrow$ & 2008 & October & 201500 & 238500 \\
\hline$\Rightarrow$ & 2008 & November & 246500 & 263500 \\
\hline
\end{tabular}

The Pinched (Optimized) Production for the above Supply Chain data occurred in Year: 2008 and Month June is : 163500 


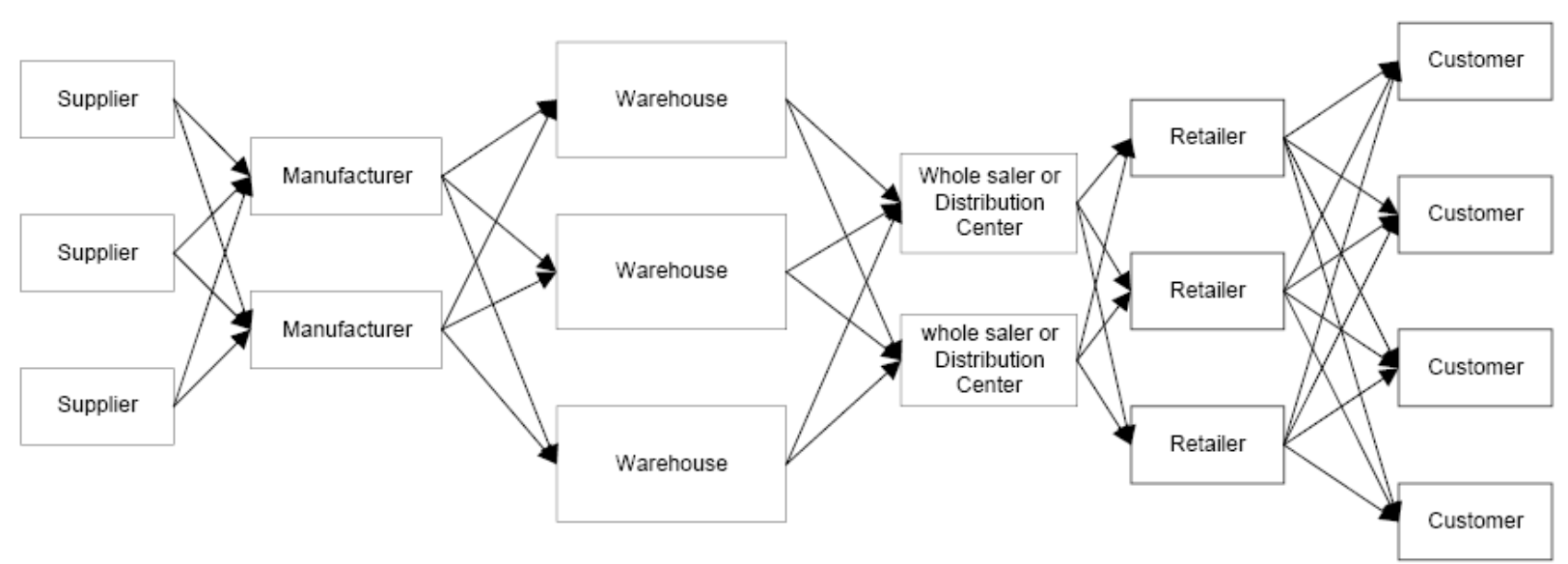

Figure 1. A Typical Supply chain (Adopted from Arnold \& Chapman, 2001)

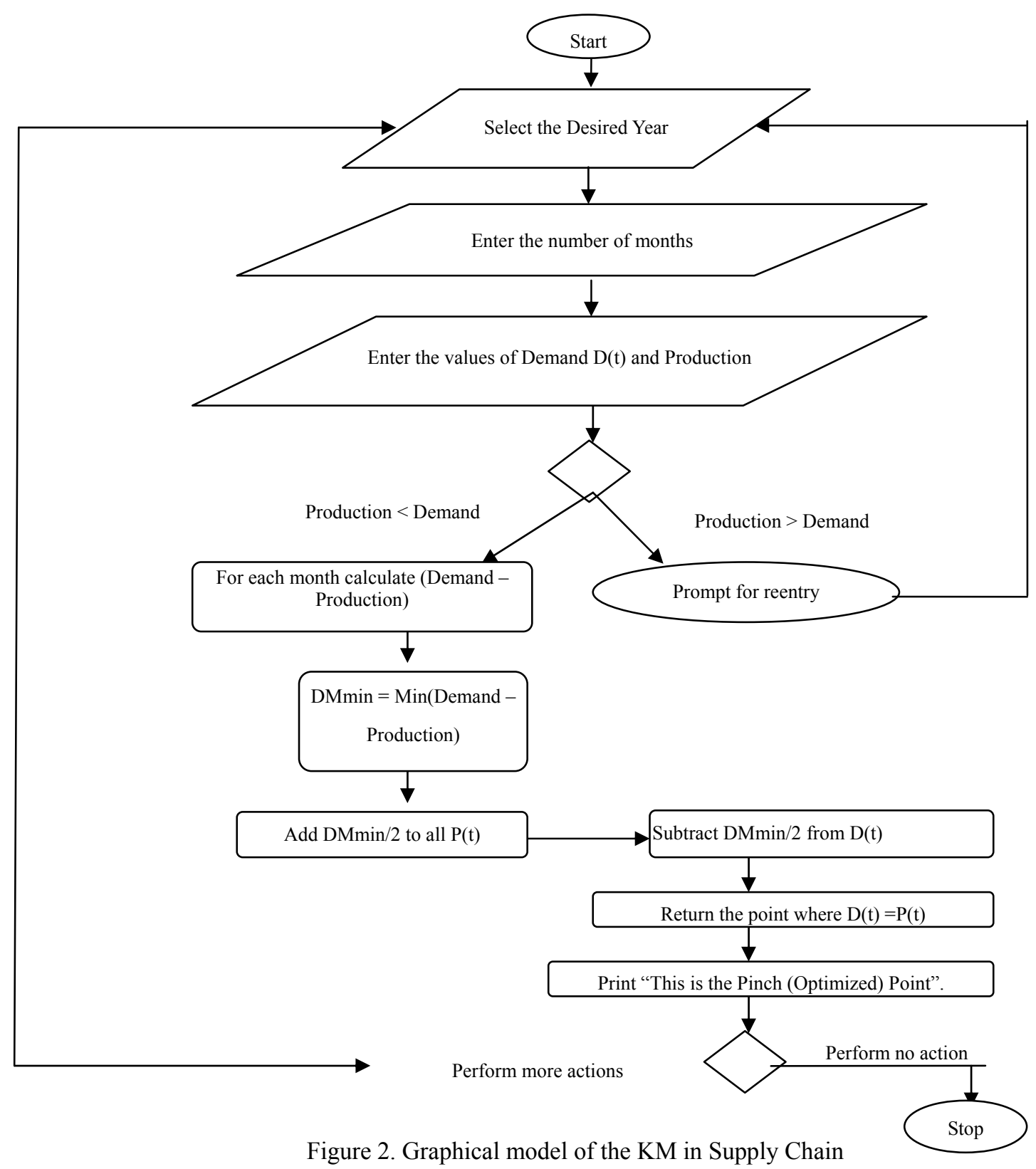

Figure 2. Graphical model of the KM in Supply Chain 


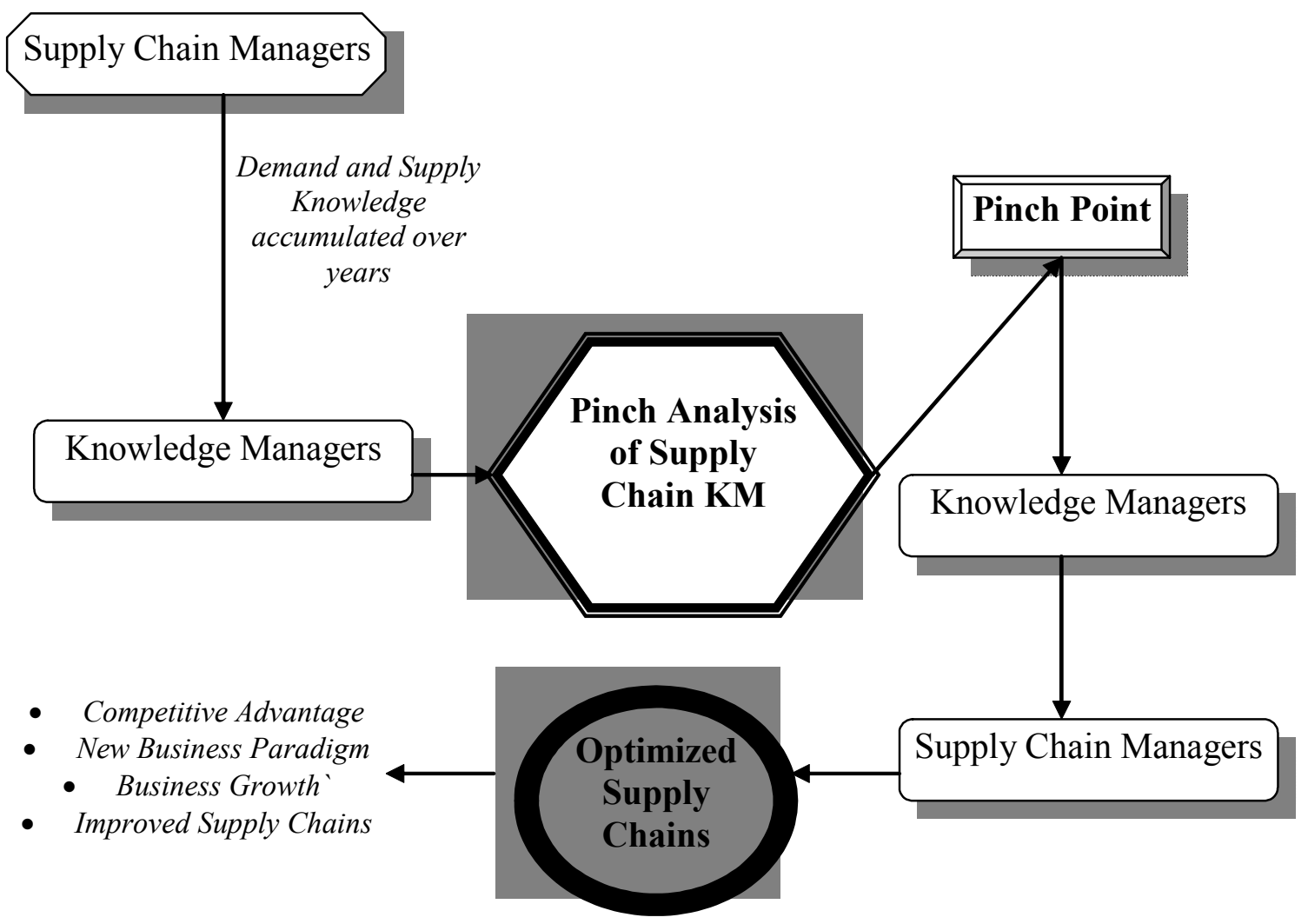

Figure 3. Architecture of the Proposed System

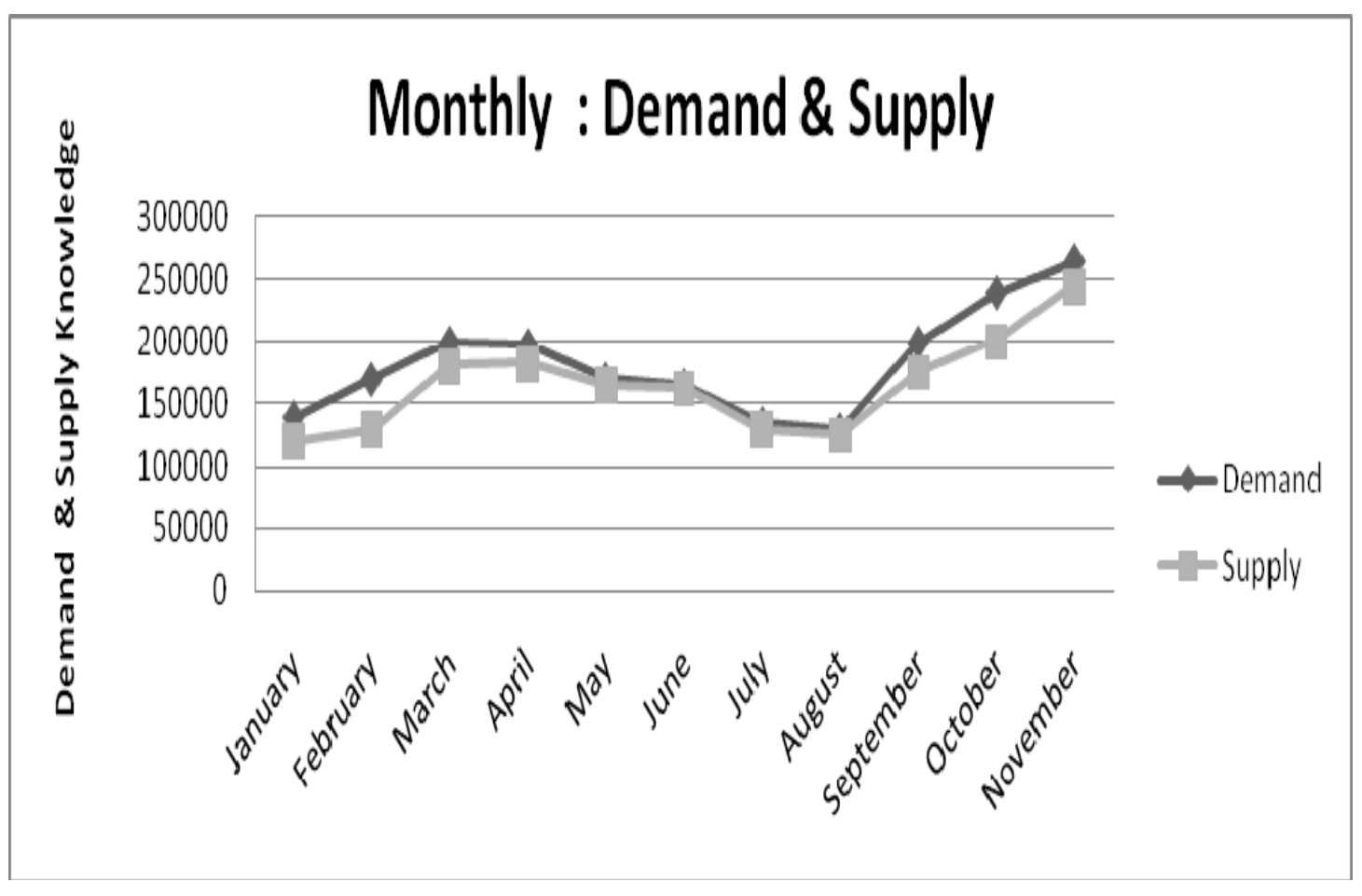

Figure 4. Chart representation of the initial data 


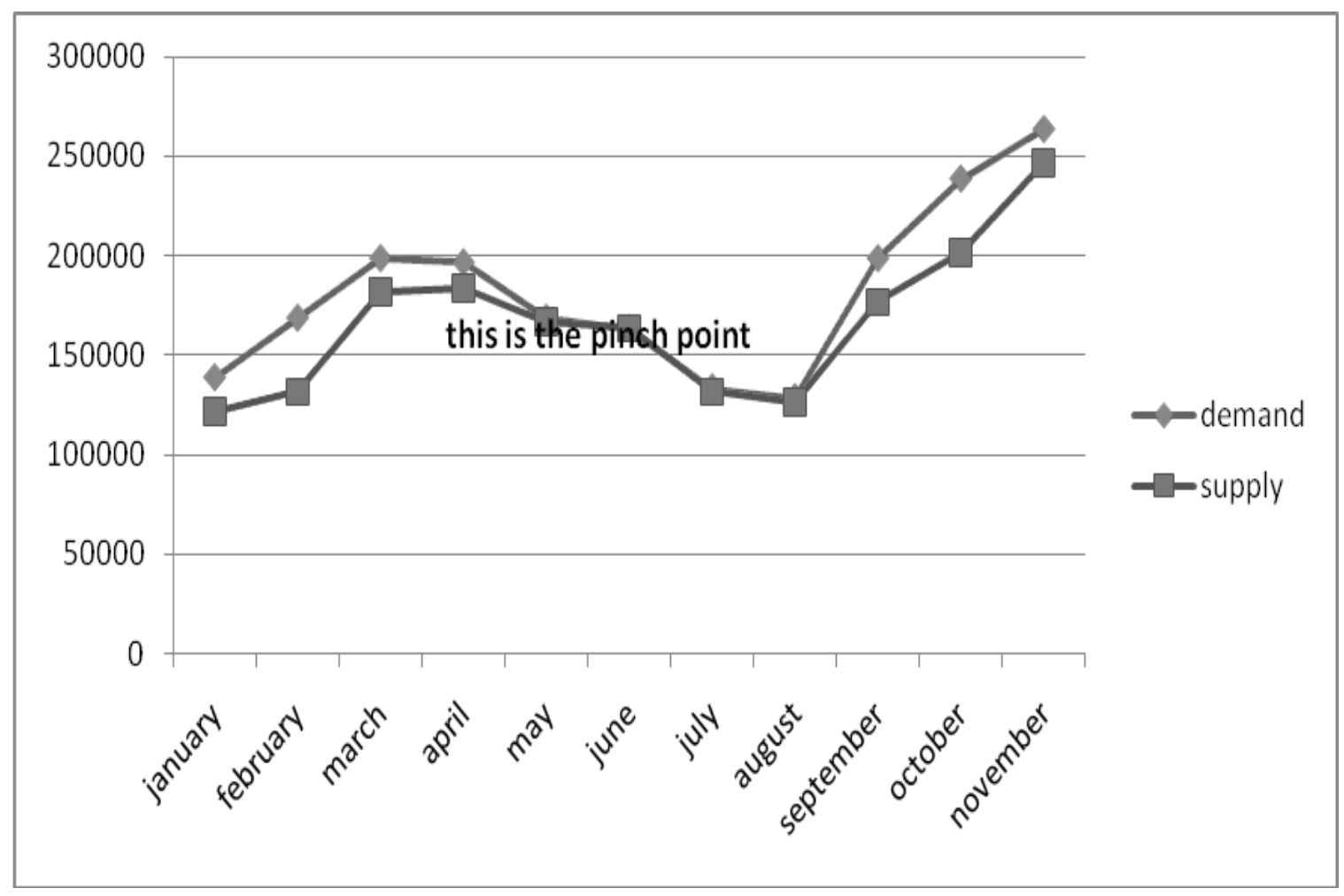

Figure 5. A chart representation of the optimized data 